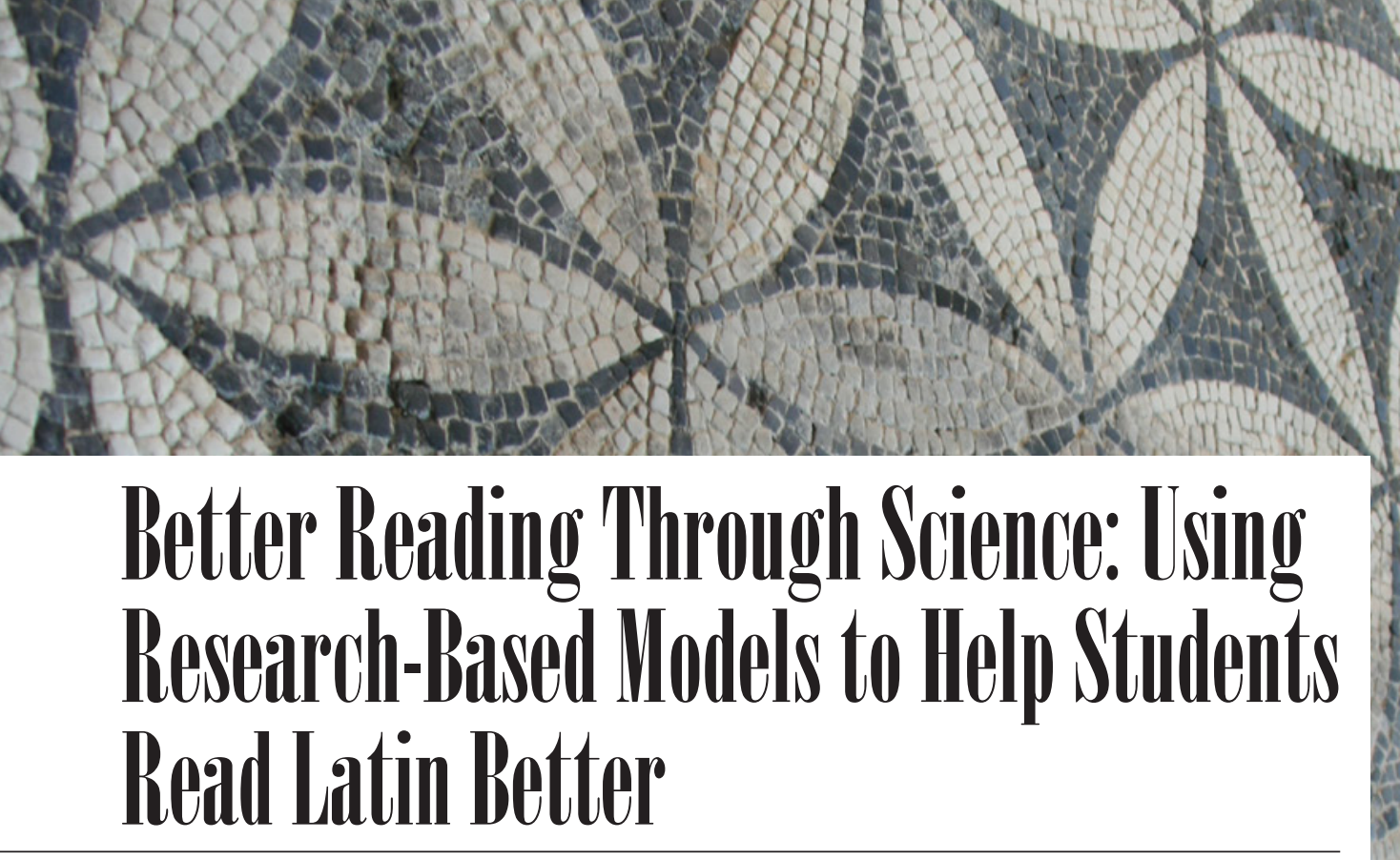

by Todd A. Wegenhart

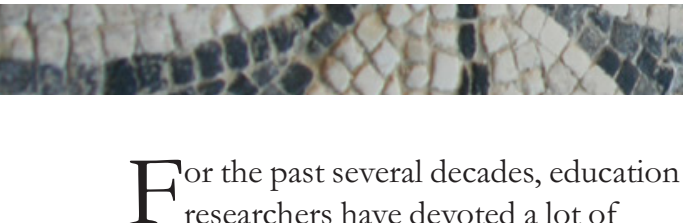
time, energy, and practice to gaining an understanding of literacy and the cognitive processes that control it. This research has developed, evidence has converged around certain findings, and teaching methods for reading and literacy have changed for the better because of it. Unfortunately the information and research, by and large, has not trickled out of the realm of reading education.

Nevertheless, there is a great deal that teachers of Classical languages can learn and gain from an understanding of the ideas that have evolved from this research. After all, reading is a key component to any Latin or Greek classroom, regardless of whether the teacher espouses a reading method, a traditional grammar-translation method, or an approach that focuses more on productive proficiency. By using the products of the past years of literacy research, Latin and Greek teachers can perform better as educators, since they will have a stronger construct for how reading works as a cognitive process and they will be more able to provide students with help and support by isolating problem skills and developing activities specifically to remedy those issues.

The major goal of this article is simple: to provide information about the proven models that exist for teaching reading in English and then to explain how that model can be applied to the teaching of Latin or Greek. In order to do that, there are some basic ideas that must first be understood in order to give this article the most meaning and usefulness that it can have for readers.

First, since the author is a teacher of Latin and of English reading, those are the languages that he will refer to throughout the article. However, it is important to recognise that educators of many foreign languages can use English reading research as a proxy for reading research in the target language. In the case of reading Latin or Classical Greek, there is not much research available on those languages specifically, so it is necessary to rely on research done in other languages to get a sense of what is needed for the Classics. It is fortunate that research has found that there is significant similarity in how the human brain learns to read and then how the brain processes printed language when those languages have similar structure and orthography. In other words, the language itself is not the key influence in how the brain learns to read, but rather how the language is written. English as a written language is based on a phonetic alphabet, wherein individual letters and combinations of those letters in text represent the sounds of the language. Since English works on the same alphabetic principle as all other alphabet-based written languages, it is possible to assume that Latin or ancient Greek, being alphabetic orthographies, would have the same or similar results if they could be studied in the same way as English has been.
Second, how intervention is performed is a key idea in this article. For teaching English reading, there are two solid methods of intervening for student needs. First is generalised systematic instruction for everyone in a class: the best way that teachers can intervene for their students is to intervene before problems ever arise by being methodical and explicit with daily instruction. Understanding of the models presented below allows a teacher to isolate and address the needs of all students and to plan class instruction accordingly. The second method of intervention is targeted intervention. This style should be crafted around the student and individualised to his or her needs; as every student will struggle in different ways, teachers should be ready to intervene in different ways to address the specifics of a student's problems. Too often will Latin teachers intervene for their students simply by saying 'study more,' 'review your vocabulary,' and 'practise your charts and paradigms' without any real knowledge of whether those things will work for a student. But in order to individualise the intervention and identify the needs of a student, teachers need some form of triage and informal assessment that allows them to see the needs of a student by isolating the required component skills that a student must have.

The models presented here and the discussions presented around them are meant to provide ways of thinking about 
both of those intervention methods. By using the models to define how Latin works as a language and how reading works as a process, a teacher is able to prevent a handful of problems through better instruction. When problems do arise, the teacher is able to use these same models as a framework for discovering where a child has gone wrong in his language learning process and then craft activities, additional lessons, and practice around those needs.

\section{The National Reading Panel}

\section{In 2000, a group called the National} Reading Panel (NRP) published its findings and described what it meant to read. The NRP was a panel of experts in reading research and education which began in 1997 under the order of the United States Congress and under the direction of the US Department of Education. For the three years of the NRP's existence, it performed a massive meta-study of reading research, compiling notes and results from hundreds of experiments done in the field of reading. What it found was that reading could be defined as the confluence of five unique skills: phonemic awareness, phonics, fluency, vocabulary, and comprehension. Defined concisely, phonemic awareness is a person's ability to recognise aurally the sounds used in a word and to manipulate those sounds as desired. For example, if an adult asks a child to say the word 'cat' without the first sound, and the child says 'at,' that child is showing solid phonemic awareness: he is able to identify what the initial sound of the word is and remove it without altering the remaining sounds. This is a very basic skill, but absolutely necessary for a child to develop phonics skills: phonics is the understanding of how letters represent the sounds of a language. With phonics skills, a child can look at the word 'cat' written on a page and recognise that the sounds of the word are $/ \mathrm{k} /, / \mathrm{a} /$, and $/ \mathrm{t} /$ and then use his phonemic awareness skills to string those sounds together and end up pronouncing the word correctly. The combination of phonemic awareness and phonics is essential in rapid and fluent reading, as well as necessary in spelling. This act of fluently recognising sounds encoded by letters and combining them to make words will be referred to from this point forward as decoding. Fluent decoding then is combined with a rich vocabulary knowledge which ultimately allows an individual to comprehend the text he or she is reading. These components are an efficient way of describing reading because they provide a model that defines the skills necessary for effective reading; it is presumed that a child who does not achieve one of the five component skills will not be able to read as desired.

The NRP has allowed reading teachers to think about what the real task of reading involves: there are multiple factors that need to be taught in order for a student to become a successful reader. The model that the NRP has presented allowed reading teachers to intervene with students who struggle to read efficiently by focusing on the components of effective reading that the student is lacking. In other words, rather than try to work with a student who is having difficulty understanding what he or she reads by providing comprehension strategies and activities that serve to refine only comprehension, reading teachers will now do analysis of the student's skills to determine where the problem actually exists and then teach to that need.

In the Latin classroom, this model is very ready to use for two key reasons. First, it helps Latin teachers realise that reading requires more than just vocabulary and syntax knowledge, and second, it not only defines skills but also sequencing. For general instruction, it is critical to start with phonemic awareness: students should hear the sounds of Latin before ever trying to read it. This can be done with audio recordings or with the teacher presenting language through scripts or with simple games that allow the students to comprehend what they are hearing, even if they cannot understand every word. Dramatised storytelling or repetition of simple commands (e.g. playing with the difference between 'discipuli, surgite' and 'discipulae, surgite') would get this across. This can quickly advance into phonics, as most students should have mastered phonemic awareness in English and can quickly transfer that skill to Latin due to similarity in sounds. Phonics can then be introduced letter by letter, just like a four or five-year old would do it. Shortly after that (again because skills should be easily transferable), this can lead to blending sounds and letters into short words (via, rex, puer, arbor) and then into longer words.
To put perspective on this idea of word decoding as a necessary skill, think of the Cambridge Latin Course (Pope, 2001). Imagine being a first year Latin student, with no prior knowledge or instruction in Latin and seeing the very first word in that textbook: Caecilius. Without phonemic awareness and phonics instruction prior to seeing this word, the student is really left to fail at pronouncing it: the pronunciation of the two $c$ sounds will likely be inconsistent, the pronunciation of the ae will be nearly impossible since this is not a letter pattern common in English, and the ius at the end will leave a student to guess as to whether it is one syllable or two. And while it is easy for an instructor to simply teach a child what the word says, that does not help the student deal with other multisyllabic words later or even short words with similar sounds.

After decoding is in the process of being mastered, teachers can begin emphasising natural speech patterns when reading, and building solid vocabulary, both leading to total comprehension. However, when a teacher encounters a student who has issues understanding Latin texts, he can use the NRP model to determine what skills a student is lacking. A teacher can go back and check the student's phonics and decoding skills, because without those skills the student will be unable to recall vocabulary (Wolf, 2007); a teacher can make sure that a student can not only sound out a Latin word but do so fluently and efficiently, thus aiding in word recognition and recall; and a teacher can check a student's vocabulary knowledge to make sure that word recognition and recall are actually present.

\section{The RAND Heuristic}

The RAND Heuristic (fig. 1) is a model presented by the RAND Reading Study Group in 2002 which provides a very different idea of what reading entails than does the NRP, but still is quite applicable to teaching English reading. The RAND Group sought to deviate from the idea that the text is the primary factor in defining comprehension and thus developed a model that separates and defines all of the factors which are important to the process. The model envisions reading comprehension as a product of the Reader, the Text, the 


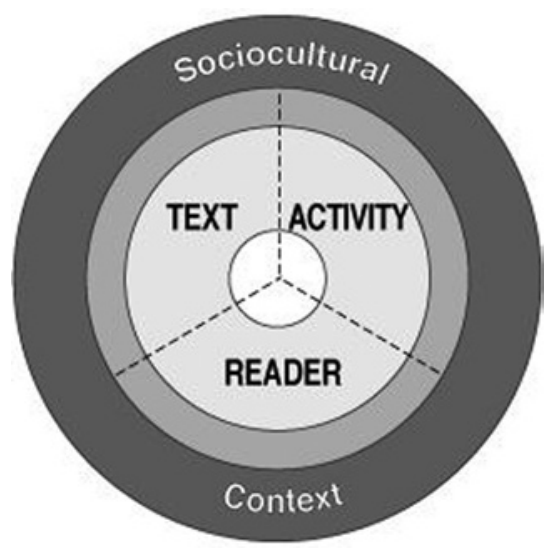

Figure 1. | The RAND Heuristic (2002).

Activity, and the Sociocultural Context of the reading. The Reader is a component that embraces the reader's prerequisite skills such as phonological skills and syntactic awareness, cognitive capacity, attention, and background knowledge. The Text is defined by its complexity, genre, organisation, and appearance. The Activity is the reader's purpose for reading and varies in how deep a text must be understood, the consequences and motivations for performance, and the supports in place for the reading. Sociocultural Context refers to larger ideas such as home support, ability to share ideas, language skills that allow for expression and understanding, etc. As defined by the RAND Group, reading comprehension becomes a far more complex concept than the initial four components of Reader, Text, Activity, and Sociocultural Context because it posits that comprehension varies from person to person, or even from day to day in the same reader, in innumerable ways. Furthermore, it creates a definition for reading comprehension that is concise and attractive, but lacks the specificity that teachers might want in a usable model. Likewise, as the model becomes less attractive due to its nature of being in permanent change, it is impossible to study and control all of the factors; reading scientists can never know if these four components are all there is because they cannot be adequately tested and determined to be the sole components. Finally, the constant changes in the model make this unreasonable for teachers since they cannot control any component in a way that will allow them to focus instruction on improving the reader. The model can be used to demonstrate the complexity of the factors weighing on reading comprehension, but cannot readily be used in a pedagogical way.

Nevertheless, while the model is difficult to use as a suggestion for how a teacher should teach, it allows the teacher to begin to understand the struggle behind good reading. Every time a student sits down to read a text, the model changes and the ratio of each part to any other is different. But knowing this, a teacher of English reading can focus on the controllable elements and try to create a level of consistency as well as empathy in the reading process. The teacher can control the element of the Reader through quality skills instruction in phonics, fluency, and vocabulary. The teacher can also define the Activity of the reading by explicitly setting the purpose and goals which are to be accomplished. And the teacher can work to limit the influence of Text on the overall task of reading by seeking consistency from text to text, but also by teaching the specifics of different genres and giving background information on sources and authors. While the teacher cannot control the Sociocultural Control entirely, he can work inside his classroom to create a social environment in which reading is valued in order to offset some of the effects that a student's outside environment might have.

A Latin teacher can use the RAND Heuristic in exactly the same way as an English teacher might. This model focuses a teacher on the concepts which he can and cannot control, allowing him to work on the controllable and to accommodate for the uncontrollable. Ultimately, any teacher can take away the idea that explicit explanation and instruction are valuable in facilitating quality reading comprehension, whether the instruction is focused on the Reader, the Text, or the Activity. A reader will succeed better when his skills have been properly developed, when he understands the source and genre of a text, when the text is at an accessible difficulty level, and when he understands what he is expected to learn and accomplish from the reading.

\section{The Simple View of Reading and The Reading Rope}

Two models with quite a bit of overlap are the Simple View of Reading (Gough and Tunmer, 1986) and the Reading Rope (Scarborough, 2001). The Simple View of Reading (SVR) seeks to define reading comprehension by defining the components which are necessary for it to occur, in this case decoding and linguistic comprehension. Simply put, without decoding skills reading comprehension cannot occur because a reader cannot access the words on the page in order to understand them. Likewise, if a reader cannot understand the linguistic elements of the text, such as syntax, vocabulary, or semantics, he will not fully understand the text, possibly despite his mastery of the phonics system and his ability to decode all of the words. This model shows a teacher that in order for a student to read successfully, there must be instruction in decoding and development in linguistic comprehension. With this, teachers have a vision of reading comprehension that is simple enough to provide a framework for conceptualising instruction.

Furthermore, the SVR seeks to identify at the most basic level the essential components of reading and not to define the various factors that influence those. Per this model, teaching reading should be as plain as teaching decoding and teaching linguistic comprehension. Unlike the RAND model, the SVR presents a model where either component can in fact be controlled.

However, the model of the SVR might be a little bit too distilled: for a teacher without extended insight to the concepts of decoding and comprehension and the knowledge of what those concepts entail, the SVR doesn't provide adequate guidance despite the fact that it is sound and controllable. Instead, teachers can easily turn to the Reading Rope model (fig. 2). This model expands the SVR into two strands of a rope: Language Comprehension (similar to SVR's comprehension component) and Word Recognition (similar to SVR's decoding component). Within each strand, Scarborough further breaks down the Rope into individual threads that define those strands and help a teacher understand the individual skills for each. For teachers of English reading, this provides a visual reminder of the complex components for reading and the number of things that must be taught to achieve success.

Similarly, teachers of Latin can use the Reading Rope with similar results. In 

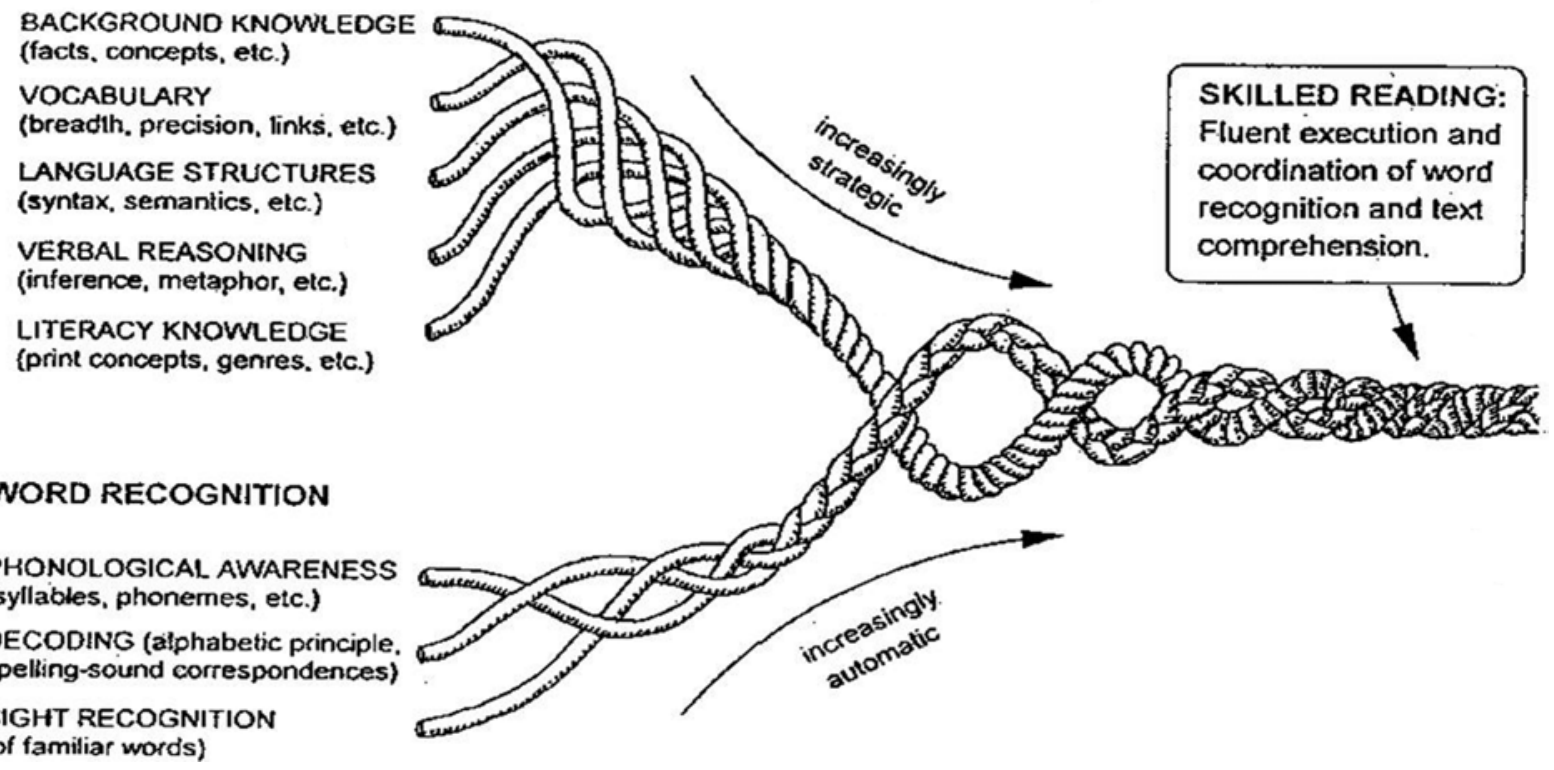

WORD RECOGNITION

PHONOLOGICAL AWARENESS (syllables, phonemes, etc.)

DECODING (alphabetic principle. spelling-sound correspondences) SIGHT RECOGNITION (of familiar words)

SKILLED READING: Fluent execution and coordination of word recognition and text comprehension.

Figure 2.|The Reading Rope (Scarborough, 2001).

an earlier article, the author discussed the use of the Reading Rope model and how all of the threads contribute to reading Latin as they would in English (Sparks \& Wegenhart, 2011). To provide an example here, a Latin teacher can consider a very simple Latin sentence: ego puellam video. On the Word Recognition strand of the Reading Rope, a reader would need to be able to use his Phonological Awareness to blend the letter sounds through the words and to understand that when this sentence is read or spoken aloud, it is three distinct words. Decoding applies to a reader being able to isolate the letter sounds of each letter correctly in order to understand the sound and the meaning. With this sentence, if a student is inconsistent in his decoding of puellam, he will generally be unable to recall the meaning, because each mistake causes his mind to process the word as something new. Sight Recognition comes in when we consider these words as high frequency and easily recognisable; a student will be able to comprehend the meaning of the sentence better when he is not weighed down with guessing or looking up the meanings of these words. And to make this a usable model for Word Recognition, all of these skills are easily teachable through repetition and simple modelling: teachers can read texts aloud to students, students can read texts to the teacher or each other, and students can have conversations that are not text based as a way to learn phonological awareness. More traditional methods like word and sentence dictation are also excellent ways of developing phonological awareness and decoding skills, since students must both recognise sounds aurally and encode them as letters to perform these tasks. An important caveat to this application for a Latin teacher, however, is the fact that being explicit with this instruction is critical: practice and repetition do not lead to good results when there is not direct feedback and previous instruction on the topics, and students need to understand exactly what is being asked of them in order to succeed.

Along the Language Comprehension strand, the same three-word sentence from above can demonstrate all of the threads that a Latin reader has to consider. The Vocabulary Knowledge thread seems straightforward but requires more than Latin-English definition and correspondence: a reader must also consider part of speech, declension, case, number, person, and tense, all as part of vocabulary. Something as simple as part of speech can mislead a student, since he could misinterpret a word like video as a second declension, ablative noun rather than a first person verb. Students may also need to sift through a variety of meanings for a word to decide what is most appropriate for the context of the sentence and paragraph, a quality which can easily be seen in the word puellam from the sentence; depending on the author, the topic of the passage, and the relationship between the speaker and the girl, the puella could simply be a young, unmarried female, or it can be someone's girlfriend as it is frequently in Catullus. On the Language Structures thread, readers again need to work with context and interpret things like case, and subject-verb agreement to make the sentence clear. Beyond that, a reader needs to understand conventional Latin word order to work through the sentence fluidly as a reader or as a translator. The Background Knowledge thread allows a reader to make assumptions about the content of the sentence based on the broad context and the specific context of the sentence; for this model, if a reader doesn't know video as a vocabulary item yet, but does know puella, he can use that background knowledge to realise that meanings like see, hear, or fight are all possible but things like eat, throw, or read are not since they do not make sense as actions that would have a girl as the direct object. The Verbal Reasoning thread allows a reader to interpret the author's intention and to place the sentence into the sequence of a larger narrative, mentally answering how this event took place and predicting why it is important to what will follow. Lastly, Literacy Knowledge gets deeper into why the author chose the word order that he did and how that affects the reader's understanding, why the sentence is so short and direct, and why the author chose to include ego rather than omit it as is conventionally done. 
Again, as with the Word Recognition strand, all of the threads of the Language Comprehension strand are teachable, both through explicit means and through more implicit means like modelling or questioning. Teachers can easily use example sentences that are at appropriate levels for their students and demonstrate how to interpret the sentence using each of these threads, and then easily give students new examples with which to practise and with which to demonstrate their skills. Use of well-written questions can also draw out student knowledge and encourage students to approach sentences in different ways, especially questions about why the author made specific choices in his composition or about how a particular sentence communicates a certain idea better than other sentences. These conversations can then roll into exercises challenging students to critique each other's writing or to alter texts to change tone or intention. But, a teacher needs to remember that these are not skills that are practised and mastered in a few sessions: they require regular repetition and re-teaching before they are really mastered.

Teachers of English reading who use this model will often use it as a reminder of what they as expert readers are doing every time they read, because these skills are automatic and fairly unnoticeable as mental processes once they are mastered. For Latin teachers, the Reading Rope can be used the same way: as a reminder of what mastery looks like and then as a tool to make sure that they are teaching all of the components of expert reading. Since not every student will be able to transfer those skills from English into Latin, and some students may never have learned them in English, this model helps teachers develop instruction that will provide support and scaffolding for students who need more help developing their skills and will provide challenging ways of thinking about a text for higher-skilled students. When a Latin teacher considers a student that he has taught who has been successful and achieved at a high level, he can likely see all of these threads in the way the student reads Latin, so it makes sense to teach these threads to all students as a means to give them the approach they need to reach similar success.

\section{The Cognitive Model}

The last model discussed here is the Cognitive Model, developed by McKenna and Stahl (2009) and shown in Figure 3. This model nicely ties with the Reading Rope model since it uses many of the same strands and threads, but it reorganises them into something more akin to the branches of a tree. The way that English reading teachers use this model is to start at the goal at the far right: Reading Comprehension. From there, a teacher can work backward to the left to break the skill of Reading Comprehension into its component parts, and then further explore those components. When teaching English, this actually becomes a useful assessment tool, because it allows a teacher a way of conceiving reading as a progression of skills rather than multiple parallel skills. For example, if a student has difficulties understanding text, a teacher can develop or use assessments that will check on Automatic Word Recognition, Language Comprehension, and Strategic Knowledge. If it is determined that the student is weak in Automatic Word Recognition, the teacher would then proceed down that branch, assessing each skill down the line until the student shows proficiency. Through this method, a teacher can isolate what a student's specific issues are with reading and develop interventions around that issue, since ultimately it is the lowest issue that is undermining the higher skills. This way, a teacher might find that a student's comprehension problems are really the result of poor decoding and little else.

A Latin teacher can certainly use this flow chart in the same way, or develop it in an appropriate way for himself or herself. One fault that a Latin teacher might find with this graphic is that it does not necessarily get into some of the critical skills of Latin that teachers understand affect a student's comprehension, such as case. However, this model gives Latin teachers a clear starting point towards determining the roots of a student's reading difficulties and isolating issues in order to structure interventions around them. Very often,

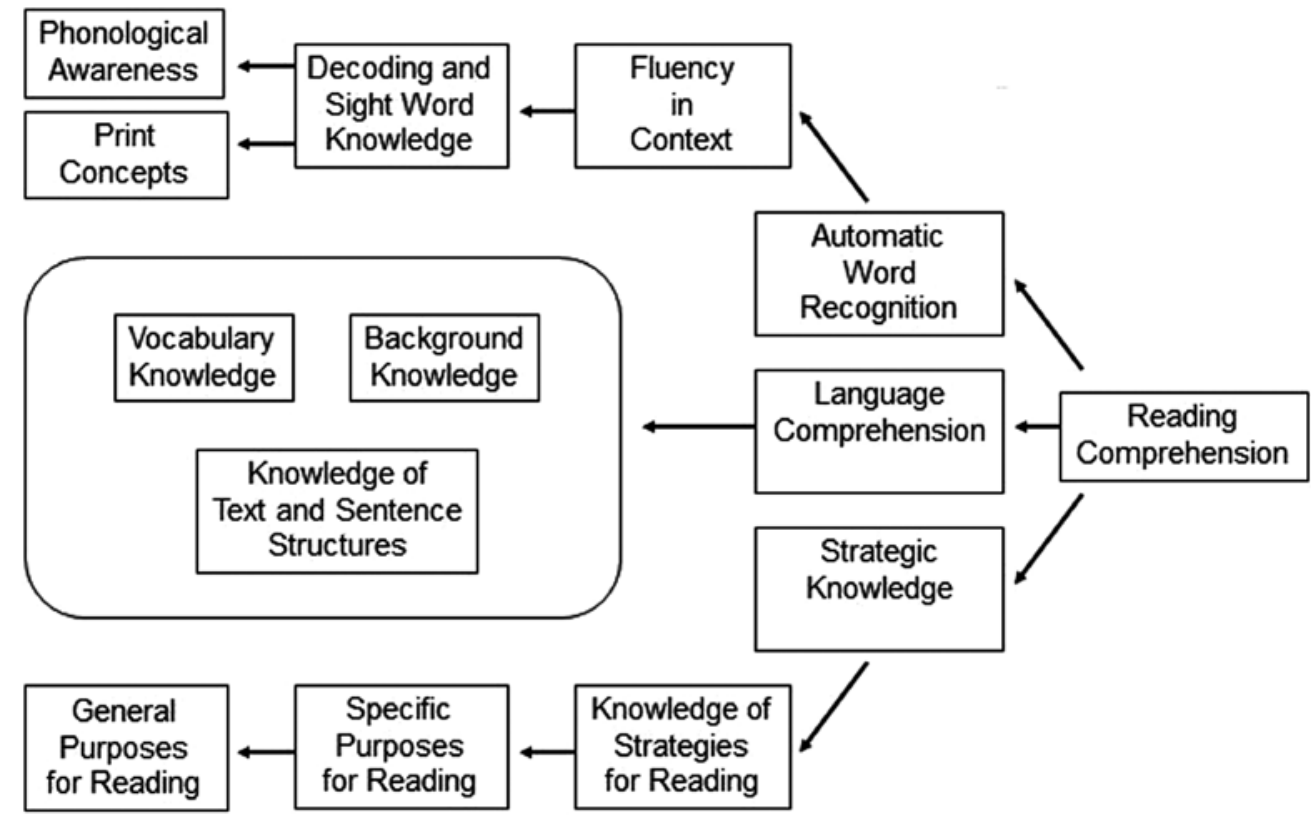

Figure 3. |The Cognitive Model (McKenna \& Stahl, 2009). 
those problems in Latin are going to come in the decoding area, the vocabulary knowledge area, or in the knowledge of text and sentence structures, since many of the other skills have cleaner overlaps with English reading and are thereby more easily transferred. However, there is no guarantee that all of the students in a class are strong English readers, so the skills may not exist in English reading to transfer; in cases such as this, Latin teachers can use this Cognitive Model to examine not the student's Latin skills, but his English skills instead, as it is very likely that a student who struggles with a skill in English will continue to struggle with that skill in a second language. Latin teachers can obviously collaborate with English teachers in these assessments since those problems are relevant to both classes.

Key in looking at these models for reading is that all of them are appropriate, research-based, and serve to help teachers understand the complexity of the task that they are asking their students to do. While none of these models is perfect for all situations and all needs, they all can be used to plan instruction, develop assessments, and design interventions in a way that supports the multiple needs that a reader has to learn to address as he reads. These models also provide teachers with a way of communicating with students how reading is both difficult and attainable through proper instruction and practice. Often Latin teachers, like many other fields, forget the work and the mental effort that it took to become proficient or expert in reading: these models, as well as many others, help teachers examine their own skills and help teach students to become experts rather than hope students will acquire these skills through transfer on their own.

Todd A. Wegenhart

Todd A.Wegenhart is a teacher of
Latin at Wyoming High School in
Cincinnati, OH, USA, holds an MSEd
in Reading Science, and is a licensed
reading specialist. Todd also serves
as the director of the Teaching
Materials and Resources Center for
the American Classical League.
wegenhartt@wyomingcityschools.
org

\section{Works Cited}

Pope, S., Bell, P., Farrow, S., Shaw, A., \& Thompson, R. (Eds.). (2001). Cambridge Latin
Course: Unit 1 (North American ed., pp. 1-2). Cambridge, UK: Cambridge University Press.

McKenna, M.C., \& Stahl, K.A.D. (2009). Assessment for reading instruction. New York: Guilford Press.

National Reading Panel. (2000). Teaching children to read: An evidence-based assessment of the scientific research literature on reading and its implications for reading instruction: Reports of the subgroups. Washington, DC: National Institute of Child Health and Human Development.

RAND Reading Study Group (2002). Reading for understanding: Toward a research and development program in reading comprehension. http:/ /www. rand.org/multi/achievementforall/reading/ readreport.html

Scarborough, H. S. (2001). Connecting early language and literacy to later reading (dis) abilities: Evidence, theory, and practice. In S. Neuman \& D. Dickinson (Eds.), Handbook for research in early literacy (pp. 97-110). New York: Guilford Press.

Sparks, L.R. \& Wegenhart, T.A. (2011). Is learning to read Latin similar to learning to read English. The Classical Outlook, 88 (2), pp. 40-47.

Wolf, M. (2007). Proust and the squid. New York: Harper Perennial. 